\title{
The number of glomeruli in Type 1 (insulin-dependent) and Type 2 (non-insulin-dependent) diabetic patients*
}

\author{
T. F. Bendtsen and J. R. Nyengaard \\ Stereological Research Laboratory, University Institute of Pathology and Second University Clinic of Internal Medicine, \\ Institute of Experimental Clinical Research, Aarhus University, Aarhus, Denmark
}

\begin{abstract}
Summary. The number of glomeruli per kidney in Type 1 (insulin-dependent) and Type 2 (non-insulin-dependent) diabetic patients was estimated by an unbiased stereological method: the fractionator. No significant differences were observed between Type 1 and Type 2 diabetic patients without severe diabetic glomerulopathy and non-diabetic patients. Diabetic patients with proteinuria who were in the early stages of diabetic nephropathy also had a normal number of glomeruli. On the other hand, a subgroup classified as Type 1 diabetic patients with severe diabetic glomerulopathy had
\end{abstract}

significantly less glomeruli compared with Type 1 diabetic patients with mild or no glomerulopathy. A probable explanation is that Type 1 diabetic patients lose glomeruli in relation to the progression of diabetic glomerulopathy. A more theoretical alternative is, however, that development of diabetic glomerulopathy is facilitated by a low number of glomeruli.

Key words: Glomerular number, diabetic nephropathy, diabetic glomerulopathy, stereology.
Brenner et al. [1] have proposed that inborn differences in numbers of nephrons contribute to the susceptibility of patients with diabetes mellitus developing renal disease: patients endowed with a reduced filtration surface area might represent the subset of diabetic patients who exhibit persistent hyperfiltration early in the course of diabetes, and later progress to uraemia. According to this hypothesis, the initially increased whole kidney glomerular filtration rate (GFR) despite reduced numbers of nephrons may be explained by marked single nephron hyperfiltration induced by diabetic metabolic abnormalities. In fact, family studies have shown that diabetic nephropathy occurs in familial clusters in Type 1 (insulindependent) [2] and Type 2 (non-insulin-dependent) diabetic patients [3]. Genetically determined low numbers of glomeruli might predispose diabetic patients to diabetic nephropathy.

Another possibility is that glomeruli disappear during the course of diabetic glomerulopathy without leaving recognizable corpuscles, analogous to other chronic renal diseases [4]. If a difference in the number of visible glomeruli between diabetic patients, depending on the severity

\footnotetext{
* Presented in part at the first meeting of the European Diabetic Nephropathy Study Group, Pisa, Italy, April 1988, and at the 23 rd annual meeting of the Scandinavian Society for the Study of Diabetes, Bergen, Norway, May 1988
}

of glomerulopathy, turned out to be significant, then comparisons of total filtration surface area and GFR would not make sense in studies where the number of glomeruli is assumed not to differ between the groups [5-8].

Kroustrup et al. [9], found a significantly increased glomerular filtration surface area per glomerulus in newly-diagnosed Type 1 diabetic patients. The result was based on observations made from a few glomeruli in one biopsy per patient. When the authors concluded that the total filtration surface area - in the whole kidney - was significantly increased in diabetic patients, they then assumed that diabetic patients do not have an abnormal number of glomeruli.

The number of glomeruli in diabetic patients has not previously been estimated. We wanted to make an unbiased and efficient estimation of the number of glomeruli in diabetic kidneys to determine whether the number of glomeruli is abnormal in diabetic kidneys $[10,11]$.

\section{Subjects and methods}

Kidneys were obtained from autopsy cases. Only one kidney was chosen per individual, the choice of left or right was arbitrary. During the years of kidney sampling most people in Denmark died in hospital [12], therefore, the sampled kidneys should constitute a representative sample of kidneys from deceased diabetic patients in Denmark. 
Table 1. The age, sex, height, surface area, kidney weight, glomerular number, diabetes duration, state of the renal function and histological classification of 25 Type 1 (insulin-dependent) diabetic patients

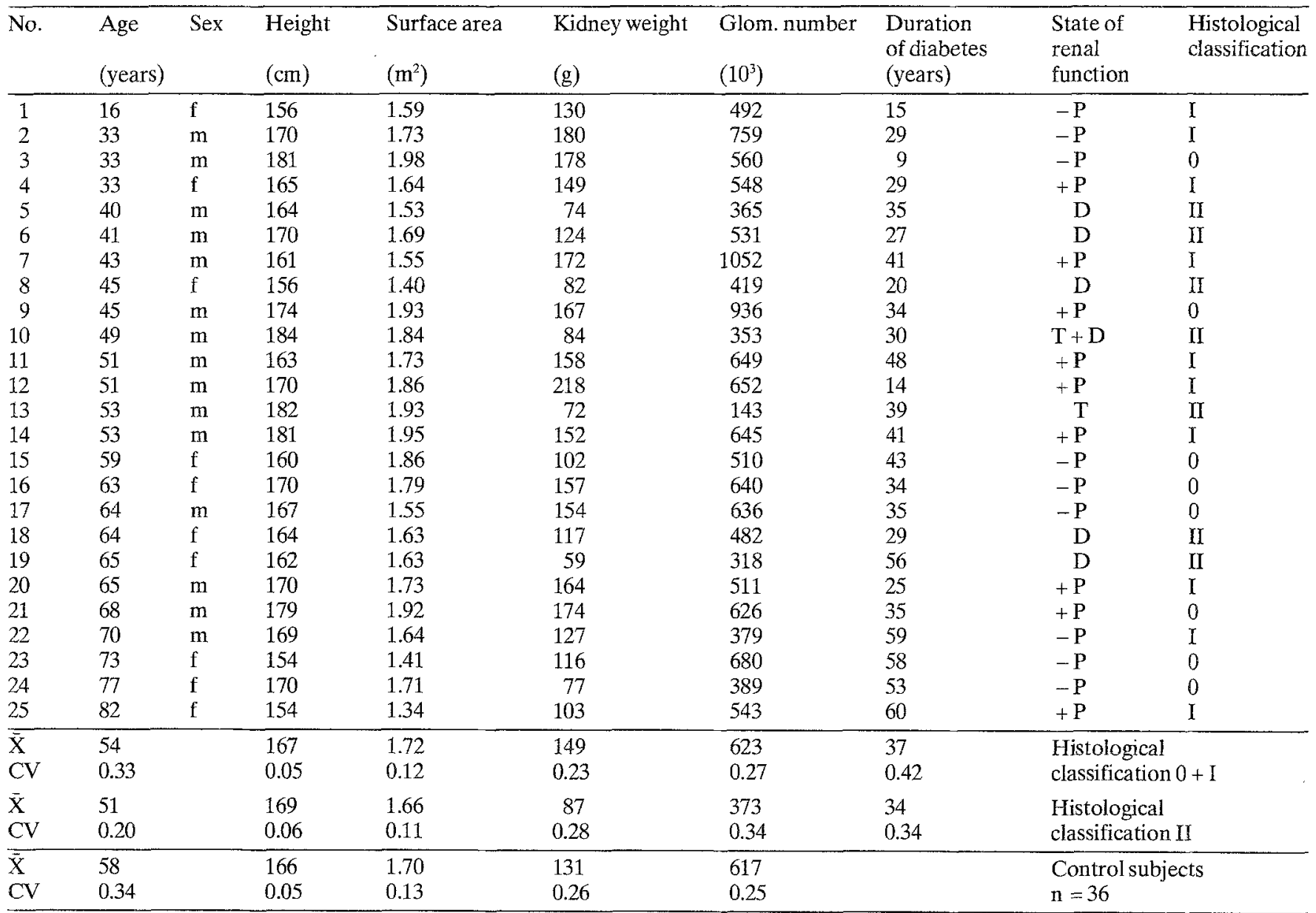

The values of control subjects are stated at the bottom. State of renal function: $-P$, no proteinuria; $+P$, proteinuria; $D$, dialysed; $T$, transplanted. Histological classification: 0 , no diabetic changes; I, solitary glomeruli with diffuse and nodular lesions; II, many glomeruli with severe diffuse and nodular lesions. Type 1 diabetic patients with severe glomerulopathy, $5,6,8,10,13,18$, and 19 are exclusively classi-

\section{Exclusion criteria}

Macro- or microscopic kidney disease other than diabetic nephropathy, disseminated malignancies, cachexia, nephrectomy, removal of renal tissue (except for small biopsies), inborn kidney malformations, or treatment with cytostatics or regional X-rays. In the case of kidney transplantation in diabetic patients, the native kidney was taken. Patients were excluded if data about blood pressure and urine-protein were absent.

Control patients were also excluded if they had been treated for hypertension or diagnosed as hypertensive during the final hospitalization or had abnormal kidney function (proteinuria = reagentstrip testing for bromphenol blue reaction; positive: over $0.3 \mathrm{~g}$ protein per 1 litre urine), as were kidneys that later showed microscopic evidence of kidney disease. The control cases have been described in more detail in an earlier publication [13]. The results of the control cases are summarized in Table 1 and Table 2.

\section{Inclusion criteria}

Differentiation of Type 1 and Type 2 diabetes from other types was made in accordance with the World Health Organisation Study Group [14]. The differentiation between Type 1 and Type 2 diabetes fied in the categories " $D$ " and " $T$ " and "II". Patient no. 8 died in uraemia without dialysis or transplantation because treatment was determined futile. Patient no. 7 had a double crus amputation: height correction $+32 \mathrm{~cm}$; weight correction $+4 \mathrm{~kg}$. Patient no. 24 was femur and crus amputated: height correction $+32 \mathrm{~cm}$; weight correction $+8 \mathrm{~kg}$ was based on the following criteria: (A) Patients treated without insulin for at least one year after diagnosis of diabetes irrespective of age, or aged above 45 years at diagnosis and survival on diet with or without oral hypoglycaemic drug therapy in a period of at least one month, were classified as Type 2 diabetic patients [15]. (B) Patients with diabetes not fulfilling the above criteria, with age at the time of diagnosis below 30 years and treated with insulin at onset of diabetes were classified as Type 1 diabetic patients, as were all insulin-treated patients with ketonuria at the time of diagnosis or later [16]. Diabetic subjects initially treated without insulin, but later with insulin, were excluded from this study.

\section{Stereological methods}

To improve immersion fixation in formaldehyde, each kidney was split in half. The kidneys were weighed after a period of fixation of 1 to 6 months. A known fraction of the whole kidney was sampled systematically at random, and in that fraction the number of glomeruli was counted. Then, the total number of glomeruli was the number of counted glomeruli in that fraction multiplied by the reciprocal sampling fraction. The practical method (fractionator) has been explained in detail in a previous publication [11], and the theoretical basis has been explained by Gundersen [17]. 
Table 2. The 39 Type 2 (non-insulin-dependent) diabetic patients shown with their age, sex, height, surface area, kidney weight, glomerular number, diabetes duration, state of renal function and histological classification

\begin{tabular}{|c|c|c|c|c|c|c|c|c|c|}
\hline No. & $\begin{array}{l}\text { Age } \\
\text { (years) }\end{array}$ & Sex & $\begin{array}{l}\text { Height } \\
(\mathrm{cm})\end{array}$ & $\begin{array}{l}\text { Surface area } \\
\left(\mathrm{m}^{2}\right)\end{array}$ & $\begin{array}{l}\text { Kidney weight } \\
\text { (g) }\end{array}$ & $\begin{array}{l}\text { Glom. number } \\
\left(10^{3}\right)\end{array}$ & $\begin{array}{l}\text { Duration } \\
\text { of diabetes } \\
\text { (years) }\end{array}$ & $\begin{array}{l}\text { State of } \\
\text { renal . } \\
\text { function }\end{array}$ & $\begin{array}{l}\text { Histological } \\
\text { classification }\end{array}$ \\
\hline 1 & 35 & $\mathrm{f}$ & 163 & 1.90 & 107 & 650 & 6 & $-\mathrm{P}$ & 0 \\
\hline 3 & 52 & $\mathrm{~m}$ & 179 & 2.00 & 172 & 681 & 5 & $-\mathrm{P}$ & 0 \\
\hline 4 & 53 & $\mathrm{~m}$ & 182 & 2.16 & 228 & 1115 & 1 & $-\mathbf{P}$ & 0 \\
\hline 5 & 53 & $\mathrm{~m}$ & 165 & 1.68 & 132 & 442 & 9 & $-\mathrm{P}$ & 0 \\
\hline 8 & 59 & f & 155 & 1.73 & 198 & 886 & 6 & $-\mathrm{P}$ & 0 \\
\hline 9 & 60 & $\mathrm{f}$ & 161 & 1.52 & 109 & 530 & 1 & $-\mathrm{P}$ & 0 \\
\hline 10 & 62 & $\mathrm{~m}$ & 182 & 2.14 & 138 & 661 & 5 & $-P$ & 0 \\
\hline 11 & 64 & $\mathrm{f}$ & 155 & 1.58 & 155 & 658 & 6 & $-P$ & 0 \\
\hline 12 & 65 & $\mathrm{~m}$ & 176 & 1.93 & 126 & 526 & 13 & $-\mathrm{P}$ & 0 \\
\hline 13 & 65 & $\mathrm{~m}$ & 162 & 1.69 & 153 & 540 & 5 & $-\mathrm{P}$ & 0 \\
\hline 18 & 66 & $\mathrm{~m}$ & 174 & 2.04 & 141 & 658 & 6 & $-\mathrm{P}$ & 0 \\
\hline 19 & 66 & $\mathrm{~m}$ & 160 & 1.51 & 134 & 632 & 2 & $-P$ & 0 \\
\hline 20 & 66 & $\mathrm{f}$ & 164 & 1.53 & 123 & 470 & 9 & $-\mathrm{P}$ & 0 \\
\hline 21 & 66 & $\mathrm{f}$ & 161 & 1.82 & 105 & 532 & 3 & $-\mathrm{P}$ & 0 \\
\hline 22 & 67 & f & 165 & 1.56 & 95 & 656 & 0.4 & $-P$ & 0 \\
\hline 23 & 68 & $\mathrm{~m}$ & 165 & 1.77 & 164 & 663 & 0.2 & $-\mathrm{P}$ & 0 \\
\hline 24 & 68 & $\mathrm{~m}$ & 175 & 2.25 & 172 & 614 & 7 & $+\mathbf{P}$ & II \\
\hline 25 & 69 & $\mathrm{f}$ & 160 & 1.62 & 161 & 548 & 15 & $-\mathbf{P}$ & I \\
\hline 26 & 70 & $\mathrm{f}$ & 166 & 1.78 & 143 & 437 & 1 & $-\mathrm{P}$ & 0 \\
\hline 27 & 71 & $\mathrm{f}$ & 158 & 1.58 & 129 & 458 & 10 & $-P$ & 0 \\
\hline 28 & 72 & $\mathrm{f}$ & 158 & 1.95 & 168 & 788 & 4 & $+P$ & I \\
\hline 29 & 73 & $\mathrm{~m}$ & 166 & 1.82 & 137 & 833 & 10 & $-P$ & 0 \\
\hline 30 & 75 & f & 148 & 1.49 & 103 & 412 & 4 & $-\mathrm{P}$ & 0 \\
\hline 39 & 89 & $\mathrm{~m}$ & 170 & 1.81 & 120 & 348 & 8 & $+\mathbf{P}$ & I \\
\hline$\overline{\bar{X}}$ & 67 & & 166 & 1.80 & 141 & 608 & 7 & \multirow{2}{*}{\multicolumn{2}{|c|}{ Type 2 diabetic patients }} \\
\hline $\mathrm{CV}$ & 0.17 & & 0.05 & 0.11 & 0.28 & 0.34 & 0.69 & & \\
\hline$\overline{\bar{X}}$ & 69 & & 165 & 1.67 & 128 & 594 & & \multirow{2}{*}{\multicolumn{2}{|c|}{$\begin{array}{l}\text { Control subjects } \\
\mathrm{n}=25\end{array}$}} \\
\hline $\mathrm{CV}$ & 0.19 & & 0.05 & 0.13 & 0.29 & 0.28 & & & \\
\hline
\end{tabular}

The values of control subjects are stated at the bottom. State of renal function: $-\mathrm{P}$, no proteinuria; $+\mathrm{P}$, proteinuria. Histological classification: 0 , no diabetic changes; I, solitary glomeruli with diffuse and nodular lesions; II, many glomeruli with severe diffuse and nodular lesions

Example: The two kidney halves were embedded in agar and placed on their cut surfaces. Each half was cut perpendicular to its length into a series of slabs at intervals of $4 \mathrm{~mm}$ with a tissue slicer. The first kidney slab was sampled among slabs no. 1-4 by means of a random number (R) between 1 and 4 . Every fourth slab in the series was sampled, i.e. $\mathrm{p}_{1}=\frac{1}{4}$. In the second series the first slab was sampled among no. $1-4$ by means of $R \pm 2$. Medulla was excised from the sampled slabs except for a narrow rim to avoid excision of glomeruli. The sampled slabs were embedded upright in agar maintaining their original order, thus forming two "shortened" kidney halves. Agar slabs were cut parallel to the length of the "shortened" kidney halves perpendicular to the foundation at intervals of $5 \mathrm{~mm}$ producing agar slabs containing kidney strips. The kidney strips were sampled according to the sampling principle described in the first step with $\mathrm{p}_{2}=\frac{1}{5}$. The precision was even further increased in this sampling step using the "Modulus System" [11]. The sampled strips were embedded in agar in their original order. They were cut perpendicular to their length at intervals of $1.5 \mathrm{~mm}$ producing agar slabs containing kidney blocks. The maximum dimensions of the kidney blocks were thus $4 \times 5 \times 1.5=30 \mathrm{~mm}^{3}$. Every seventh kidney block was sampled as described above, i.e. $p_{3}=\frac{1}{7}$. These kidney blocks were dehydrated in graded alcohol, embedded in plastic (JB-4, Polysciences, Inc., Warrington, Pa., USA) and serially sectioned on an LKB Historange microtome with a section thickness of $15 \mu \mathrm{m}$. Every eighth section (sampling section) was sampled systematically at random, i.e. $\mathrm{p}_{4}=\frac{1}{8}$. At this step the total fraction sampled of the renal cortex 


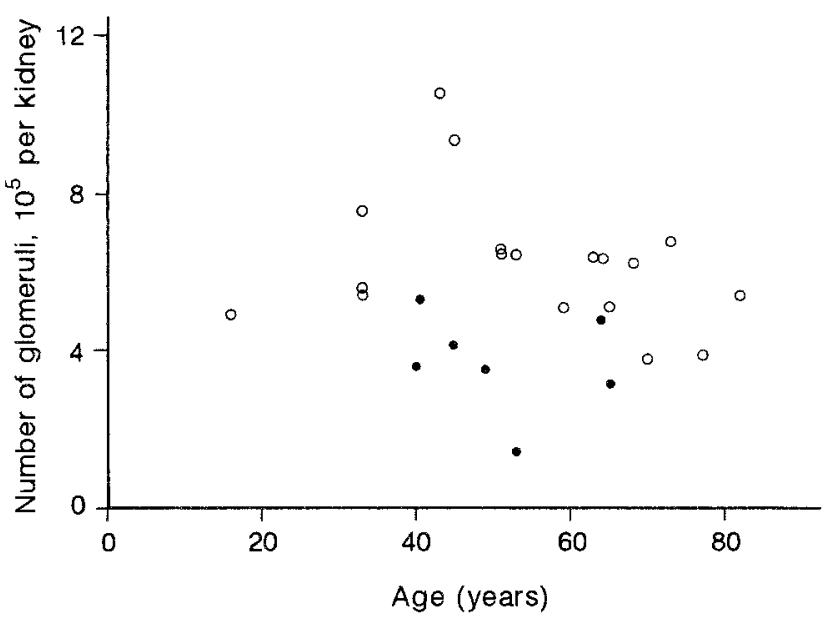

Fig. 1. The number of glomeruli in the group of Type 1 (insulindependent) diabetic patients with mild or no glomerulopathy $(0)$ is not correlated to age. Patients with severe glomerulopathy are indicated by $(\bullet)$

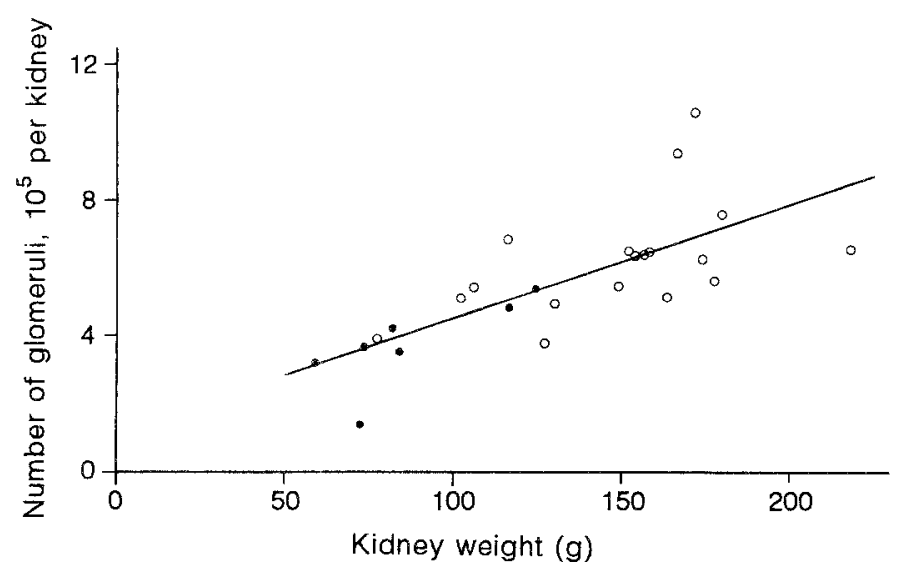

Fig. 2. The number of glomeruli in the Type 1 (insulin-dependent) diabetic patients with mild or no glomerulopathy $(0)$ regresses significantly with kidney weight. The slope is 3300 glomeruli per gram kidney weight. The Type 1 diabetic patients with severe glomerulopathy are indicated by (*)

was: $\mathrm{f}_{\mathrm{n}}=\frac{1}{4} \times \frac{1}{5} \times \frac{1}{7} \times \frac{1}{8}=\frac{1}{1120}$. The section succeeding a sampling section was also collected, and designated the look-up section. The sections were stained with periodic acid Schiff.

Two standard light monocular microscopes with mirrors were used to project the fields of vision side by side onto a table in a dark room. A counting grid was drawn on the table in the projected field of vision of the first microscope. The sampling section was placed in the first microscope and the look-up section in the second microscope. The stage of the first microscope was moved by a motor in predetermined, equidistant steps in two orthogonal directions making the counting grid cover a known fraction of the sampling section, $f_{a}$. The linear magnification of $115 \times$ and total grid area of $59,731 \mathrm{~mm}^{2}$ resulted in an area of the section covered by the grid of $\frac{59,731}{115 \times 115}=4.52 \mathrm{~mm}^{2}$. The motor was adjusted to step $3.27 \mathrm{~mm}$ along the length of the microslide and $3.05 \mathrm{~mm}$ orthogonal to the length. Therefore the fraction of the section area covered by the grid was: $f_{a}=\frac{4.52}{3.27 \times 3.05}=0.45$. The fraction of the renal cortex sampled at this step was $\frac{1}{1120} \times 0.45 \approx \frac{1}{2500}$.
A glomerulus was counted, $\mathrm{Q}^{-}$, only if it appeared in the sampling section and not in the look-up section: this event occurs only once per glomerulus in the section series. Thus all glomeruli were sampled with an equally known probability [18]. Glomeruli were only counted if they were surrounded by intact cortex. Glomeruli too close to either artificially cut edges or surfaces were excluded for counting by means of a specific counting rule [11]. An arbitrary point indicated on the grid was used to estimate the fraction of the sampled cortex sections used for glomerular counting, $\Sigma \mathrm{P}_{\mathrm{f}} / \mathrm{P}_{\mathrm{s}}$. $\mathrm{P}_{\mathrm{s}}$ was the total number of times the arbitrary point hit renal cortex. $P_{f}$ was the total number of times the point hit cortex used for glomerular counting. In our example $\Sigma Q^{-}=141, P_{f}=105, P_{s}=195$

$$
\begin{aligned}
\mathrm{N}(\text { glom }) & =\frac{1}{\mathrm{f}_{\mathrm{n}}} \times \frac{1}{\mathrm{f}_{\mathrm{a}}} \times \frac{\mathrm{P}_{\mathrm{s}}}{\mathrm{P}_{\mathrm{f}}} \times \Sigma \mathrm{Q}^{-}=1120 \times \frac{1}{0.45} \times \frac{195}{105} \times 141 \\
& \approx 652 \times 10^{3}
\end{aligned}
$$

$\mathrm{N}$ (glom) was the estimate of the total number of glomeruli in the kidney. All glomerular structures were counted - both open and occluded glomeruli.

The total variation $\left(\mathrm{CV}_{\text {tot }}=\frac{\mathrm{SD}}{\text { mean }}\right)$ of the number of glomeruli in control subjects and diabetic patients was within the range of 25 to $34 \%$ (Table 1 and 2). $\mathrm{CV}_{\text {tot }}$ resulted from biological variation $\left(C V_{b i o}\right)$, and variation of the estimates due to the stereological method $\left(\mathrm{CE}_{\mathrm{ste}}\right): \mathrm{CV}^{2}{ }_{\text {tot }}=\mathrm{CV}_{\text {bio }}^{2}+\mathrm{CE}_{\text {ste }}^{2}[19]$. The coefficient of error $\left(\mathrm{CE}_{\text {ste }}=\frac{\mathrm{SEM}}{\text { mean }}\right)$ of the method was estimated to $4.8 \%$ [13]. Thus, the total variation of the number of glomeruli in a group of patients can almost be completely ascribed to true biological variation of the number of glomeruli among the individuals in the group of patients.

\section{Histological classification}

A very experienced pathologist made a semiquantitative light microscopical classification of all kidneys without knowledge of the patient category. Classifications were 0 : no diabetic changes; I: solitary glomeruli with diffuse and nodular lesions; II: many glomeruli with diffuse and nodular lesions.

All control subjects were classified as 0. In "Results" we used only two categories for each type of diabetes: Patients from II with severe glomerulopathy (SGP) and patients from 0 and I with no or mild glomerulopathy (NMGP).

\section{Clinical classification}

All diabetic patients have been classified into four groups: - P: no proteinuria; + P: proteinuria; D: dialysed patients; T: kidney transplanted patients.

Body surface area was estimated using the method of DuBois and DuBois [20]. Patients with double sided crus or femur amputation were corrected for body length and weight, and patients with unilateral femur amputation were corrected for body weight, before estimating body surface area.

\section{Statistical analysis}

Student's unpaired $t$-test, standard multiple regression analysis and multiple hierarchical regression analysis [21], with a two-tailed significance level of 0.05 were used. Comparison of the slopes of the regression lines and their intersection with the ordinate was performed in accordance with Lentner [22].

\section{Results}

The data of the 37 control subjects have previously been tabulated [13]. Comparisons between control subjects and diabetic patients were performed after age- and sex- 


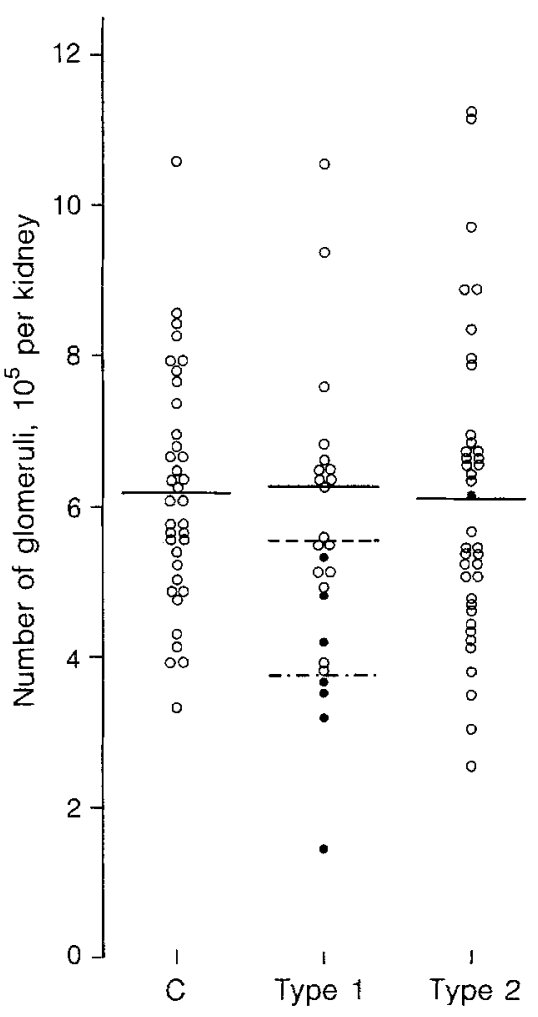

Fig.3. The individual and the mean values of the number of glomeruli for 36 control subjects (C) from Nyengaard and Bendtsen (13), for the whole group of Type 1 (insulin-dependent) diabetic patients (---), for the 18 Type 1 diabetic patients without severe glomerulopathy (-), for the seven Type 1 diabetic patients with severe glomerulopathy (----) and for the 38 Type 2 (non-insulin-dependent) diabetic patients without severe glomerulopathy. The mean value of number of glomeruli in the last group and the number of glomeruli in the single Type 2 diabetic patient with severe glomerulopathy do coincide. Patients with severe glomerulopathy are indicated by $(\bullet)$, whereas patients without severe glomerulopathy are indicated by $(0)$

matching: 36 of the control subjects were compared to the 25 Type 1 diabetic patients, and 25 of the control subjects were compared to the 39 Type 2 diabetic patients. The mean number and coefficients of variation in control subjects are listed at the bottom of Tables 1 and 2 . In the control subjects the number of glomeruli shows significant negative regression with age $(r=0.35,2 p<0.05)$ and shows significant positive regression with kidney weight $(r=0.68,2 p<0.05)$.

Table 1 displays the data of the Type 1 diabetic patients, and the data of the Type 2 diabetic patients are listed in Table 2.

Eighteen Type 1 diabetic patients had no or mild glomerulopathy (NMGP). Their mean number of glomeruli of $623 \pm 168 \times 10^{3}$ showed no significant difference compared to that of control subjects of $617 \pm 155 \times 10^{3}$ $(2 p>0.05)$. The NMGP group showed no significant regression in number of glomeruli with age (Fig. 1; $r=0.29$, $2 p>0.05$ ). Employing hierarchical regression analysis the NMGP group showed significant positive regression in the number of glomeruli with kidney weight (Fig.2; $r=0.52,2 p<0.05$ ) even after elimination of the influence of age and body surface area.
Comparison of the mean number of glomeruli of the 18 Type 1 diabetic patients classified as NMGP $\left(623 \pm 168 \times 10^{3}\right)$, with the seven classified as severe glomerulopathy $\left(373 \pm 126 \times 10^{3}\right)$, showed a significant difference of $40 \%$ (Fig. 3; $2 p<<0.05$ ).

The mean number of glomeruli of the nine Type 1 diabetic patients with $(+\mathrm{P})$ proteinuria $\left(685 \pm 185 \times 10^{3}\right)$ did not differ significantly from the mean number of glomeruli of the nine Type 1 diabetic patients without $(-\mathrm{P})$ proteinuria $\left(561 \pm 130 \times 10^{3}\right)(2 p>0.05)$.

The NMGP group of Type 2 diabetic patients showed no significant difference in number of glomeruli $\left(608 \pm 205 \times 10^{3}\right)$ when compared to control subjects $\left(594 \pm 164 \times 10^{3}\right)(2 p \gg 0.05)$, but they showed significant negative regression in the number of glomeruli with age (Fig. 4; $r=0.42, p<0.05$ ) and positive regression in the number of glomeruli with kidney weight (Fig. $5 ; r=0.70$, $2 p \ll 0.05$ ), and also in the number of glomeruli with body surface area $(r=0.42,2 p<0.05)$ even after elimination of the influence of age. The NMGP group of Type 2 diabetic patients showed significant negative regression in the number of glomeruli with known diabetes duration $(r=0.33,2 p<0.05)$, without correction for age influence. The slope of the regression line of glomerular number with age, does not show a significant difference between Type 2 NMGP diabetic patients and the matched control subjects $(2 p>0.85)$. The intersections of the respective regression lines with the ordinate also show no significant difference $(2 p>0.95)$. The co-variation of age and diabetes duration has an $r$-value of 0.29 . With the number of glomeruli being unknown, the two patients contributing the most to this co-variation were removed, which reduced the $r$-value to 0.20 . At that point the regression of the number of glomeruli with age was no longer significant $(2 p>0.05)$.

The mean number of glomeruli of the six Type 2 diabetic patients with $(+\mathrm{P})$ proteinuria $\left(566 \pm 150 \times 10^{3}\right)$ did not differ significantly from the mean number of glomeruli of the 33 Type 2 diabetic patients without $(-P)$ proteinuria $\left(610 \pm 212 \times 10^{3}\right)(2 p>0.05)$. Only one Type 2 diabetic patient was classified as having severe glomerulopathy.

\section{Discussion}

The number of glomeruli in kidneys from Type 1 and Type 2 diabetic patients with no or mild glomerulopathy did not differ significantly from non-diabetic control subjects. On the other hand, a subgroup of the Type 1 diabetic patients died in a severe state of renal function with severe glomerulopathy: this group had significantly fewer glomeruli compared to Type 1 diabetic patients with no or mild glomerulopathy. It is not possible to decide whether the group of diabetic patients who died with severe nephropathy had relatively few glomeruli at onset of diabetes, as proposed by Brenner et al. [1], or lost glomeruli during the course of diabetic renal disease. However, three important points contest the validity of the hypothesis of Brenner: 


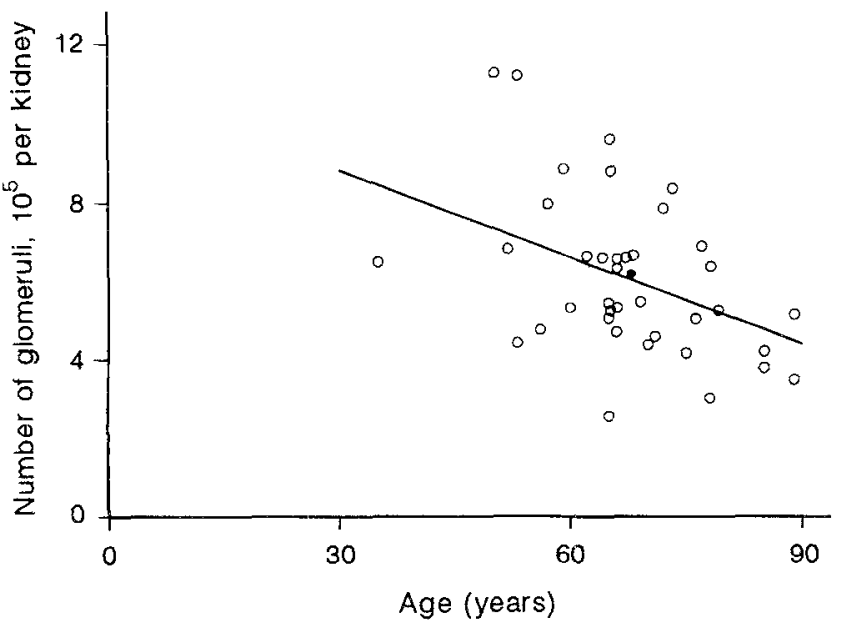

Fig.4. In Type 2 (non-insulin-dependent) diabetic patients with mild or no glomerulopathy $(0)$, the number of glomeruli declines significantly with age. The slope is -7400 glomeruli per year. Only one patient has severe glomerulopathy $(\bullet)$

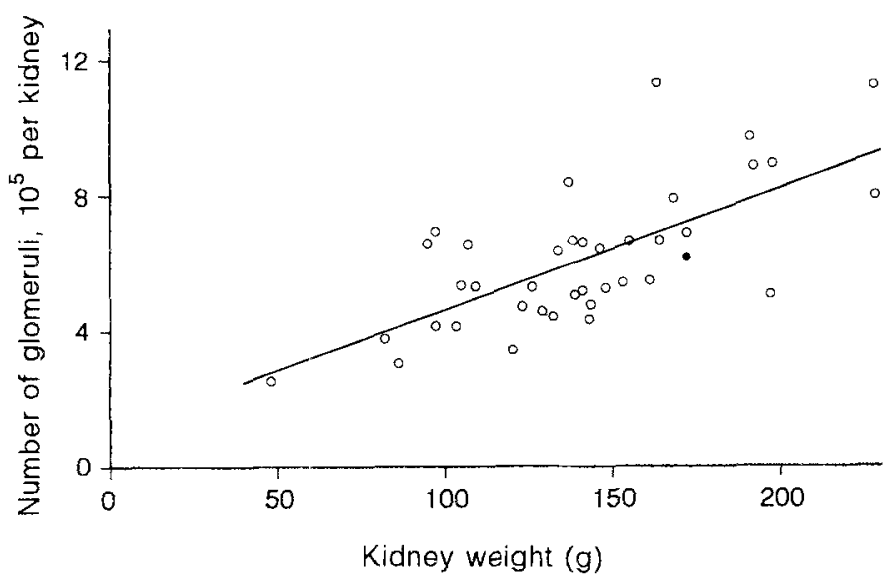

Fig.5. In Type 2 (non-insulin-dependent) diabetic patients with mild or no glomerulopathy $(0)$, there is a significant regression of the number of glomeruli with kidney weight. The slope is 3500 glomeruli per gram kidney weight. Only one patient has severe glomerulopathy $(\bullet)$

Firstly, after many years of diabetes some diabetic patients develop clinically manifest diabetic nephropathy with persistent proteinuria and declining GFR [23]. Without antihypertensive treatment uraemia develops on average 4 years after the debut of clinically manifest diabetic nephropathy [24]. In our material there was no difference in the number of glomeruli when patients classified as "no proteinuria $(-\mathrm{P})$ " were compared with patients classified as "proteinuria $(+\mathbf{P})$ ", either for the group of Type 1 or Type 2 diabetic patients. These observations support the explanation that glomeruli disappear in the course of severe diabetic glomerulopathy. There is, however, also the possibility that the decrease in glomerular number in patients on hemodialysis or having been transplanted is related to renal replacement therapy.

Secondly, Moritz and Hayman [4] found that glomeruli disappear in the course of chronic renal disease such as chronic diffuse glomerular nephritis and arteriosclerotic disease. They also produced unilateral renal damage in rabbits by means of X-rays and experimental hydronephrosis. They found that $70 \%$ of the glomeruli in the damaged kidney disappeared when compared to the normal kidney. This also suggests that fewer glomeruli in diabetic kidneys are a result of diabetic renal disease, contrary to the hypothesis of Brenner et al. [1].

Finally, Gundersen and Østerby [25] observed that long-term diabetic patients showed a considerably increased relative number of occluded glomeruli compared with control subjects, and they also observed that the relative number of occluded glomeruli correlated closely to the duration of diabetes.

Hirose et al. [6] observed a very close correlation between GFR and glomerular filtration surface area in Type 1 diabetic patients with less than 5 years duration of diabetes. Ellis et al. [5] and Østerby et al. [7, 8] observed the same correlation in a sample of diabetic patients with long duration of diabetes and clinically manifest diabetic nephropathy, though not uraemic. The authors assumed that no glomeruli disappeared in the course of the renal disease. Their studies contained no end-stage diabetic patients, whereas all our Type 1 diabetic patients with severe glomerulopathy were uraemic. Thus our results support the above-mentioned assumptions.

Kroustrup et al. [9] observed a significant increase in glomerular filtration surface area $(80 \%)$ per nephron in newly-diagnosed Type 1 diabetic patients compared with control subjects. The authors assumed a significant increase in the total glomerular filtration surface area in diabetic patients from this observation, and thus required that the number of glomeruli did not differ between the groups. Our results are in apparent support of that requirement.

Supposedly, the regression of glomerular number with diabetes duration in Type 2 NMGP diabetic patients is the result of ageing. Occluded glomeruli have been observed in column formations perpendicular to the kidney surface in Type 1 diabetic patients with severe glomerulopathy [26]. This finding suggests that an extraglomerular factor (probably atherosclerosis) causes occlusion and eventually loss of glomeruli in diabetic glomerulopathy. It would seem that such an extraglomerular factor does not have much effect in as early a stage as Type 2 NMGP diabetic patients. The lack of an age effect in the number of glomeruli among the NMGP Type 1 diabetic patients is most reasonably explained by the smaller representation of older patients in this group of 18 patients.

The correlation of the number of glomeruli and age has an $r^{2}$ value as low as $10 \%$, i.e. that age may "explain" about $10 \%$ of the observed variation in glomerular number. This means that either the effect of age on the number of glomeruli is not pronounced, or otherwise the impact of other variables tends to obscure the observable correlation of the number of glomeruli and age.

In conclusion, diabetic patients in general do not have an abnormal number of glomeruli at onset of diabetes. Glomeruli seem to disappear in the course of severe diabetic glomerulopathy, but the theoretical possibility remains that diabetic patients with fewer glomeruli are predisposed to develop diabetic renal disease. 
Acknowledgements. Ms A. Larsen, Ms A. Nielsen and Ms L. Nielsen are gratefully acknowledged for technical assistance. We are also most grateful for the help and encouragement of H. J. G. Gundersen. Also, we thank chief pathologist Dr. P. Ottosen for his classification of all the kidneys used in our study. The study was supported by the Danish Diabetes Association, the Danish Medical Research Council, Fonden af 1870, Fonden af 17-12-1981, Fonden til Lagevidenskabens Fremme, Fru Ruth I.E. Kønig-Petersens Forskningsfond, Kong Christian den Tiendes Fond, Nyreforeningens Forskningsfond, and Aarhus University Research Foundation.

\section{References}

1. Brenner BM, Garcia DL, Anderson S (1988) Glomeruli and blood pressure. Less of one, more the other? Am J Hypertens 1: 335-347

2. Seaquist ER, Goetz FC, Rich S, Barbosa J (1989) Familial clustering of diabetic kidney disease. New Engl J Med 320: 11611165

3. Pettitt DJ, Saad MF, Bennett PH, Nelson RG, Knowler WC (1990) Familial predisposition to renal disease in two generations of Pima Indians with Type 2 (non-insulin-dependent) diabetes mellitus. Diabetologia 33:438-443

4. Moritz AR, Hayman JM (1934) The disappearance of glomeruli in chronic kidney disease. Am J Pathol 80: 505-518

5. Ellis EN, Steffes MW, Goetz FC, Sutherland DER, Mauer SM (1986) Glomerular filtration surface in type 1 diabetes mellitus. Kidney Int 29: 889-894

6. Hirose K, Tsuchida H, Østerby R, Gundersen HJG (1980) A strong correlation between glomerular filtration rate and filtration surface in diabetic kidney hyperfunction. Lab Invest 43: $434-437$

7. Østerby R, Parving H-H, Nyberg G et al. (1988) A strong correlation between glomerular filtration rate and filtration surface in diabetic nephropathy. Diabetologia 31: 265-270

8. $\varnothing$ sterby $\mathrm{R}$, Parving $\mathrm{H}-\mathrm{H}$, Hommel E, Jørgensen HE, Løkkegaard H (1990) Glomerular structure and function in diabetic glomerulopathy. Early to advanced stages. Diabetes 39: 10571063

9. Kroustrup JP, Gundersen HJG, Østerby R (1977) Glomerular size and structure in diabetes mellitus. III. Early enlargement of the capillary surface. Diabetologia 13:207-210

10. Bendtsen TF, Nyengaard JR (1989) Unbiased estimation of particle number using sections - an historical perspective with special reference to the stereology of glomeruli. J Microsc 153: 93-102

11. Nyengaard JR, Bendtsen TF (1990) Glomerular number in a range of animals estimated by a simple and unbiased stereological method. Acta Stereol 2:243-258

12. The Danish National Board of Health (1988) Causes of death in Denmark 1986. The Danish National Board of Health, Copenhagen
13. Nyengaard JR, Bendtsen TF (1992) Number and size of glomeruli, kidney weight and body surface area in normal human beings. Anat Rec 232: 194-201

14. WHO Study Group on diabetes mellitus (1985) Technical Report Series no. 727, World Health Organization, Geneva

15. Cahill GF, McDevitt HO (1981) Insulin-dependent diabetes mellitus; the initial lesion. N Engl J Med 304: 1454-1464

16. Green A, Hougaard P (1983) Epidemiological studies of diabetes mellitus in Denmark: 4. Clinical characteristics of insulintreated diabetes. Diabetologia 25:231-234

17. Gundersen HJG (1986) Stereology of arbitrary particles: a review of unbiased number and size estimators and the presentation of some new ones, in memory of William R. Thompson. J Microsc 143: 3-45

18. Sterio DC (1984) The unbiased estimation of number and sizes of arbitrary particles using the disector. J Microsc 134: 127-136

19. Gundersen HJG, Østerby R (1991) Optimizing sampling efficiency of stereological studies in biology: or 'Do more less well.' $\mathrm{J}$ Microsc 121: 65-73

20. Dubois D, Dubois EF (1916) A formula to estimate the approximate surface area if height and weight be known. Archs Int Med 17: $863-871$

21. Kim J-O, Kohout FJ (1975) Multiple regression analysis: subprogram regression. In: Nie NH, Hull CH, Jenkins JG, Steinbrenner $\mathrm{K}$, Bent DH (eds) Statistical package for the social sciences, 2 nd edn., McGraw-Hill, New York, pp 333-340

22. Lentner C (ed) (1982) Geigy scientific tables, vol.2. Ciba-Geigy, Basle, pp 214-215

23. Parving H-H, Schmidt UM, Friisberg B, Bonnevie-Nielsen V, Andersen AR (1981) A prospective study of glomerular filtration rate and arterial blood pressure in insulin-dependent diabetics with diabetic nephropathy. Diabetologia 20:457-461

24. Kussman MJ, Goldstein HH, Gleason RE (1976) The clinical course of diabetic nephropathy. JAMA 236: 1861-1863

25. Gundersen HJG, $\varnothing$ sterby R (1977) Glomerular size and structure in diabetes mellitus. II. Late abnormalities. Diabetologia 13: 43-48

26. Hørlyck A, Gundersen HJG, Østerby R (1986) The cortical distribution pattern of diabetic glomerulopathy. Diabetologia 29: 146-150

Received: 3 March 1992

and in revised form: 30 April 1992

Dr. T.F. Bendtsen

Stereological Research Laboratory

Bartholin Building

Aarhus University

DK-8000 Aarhus C

Denmark 